WONDERS OF THE WORLD

\title{
WESTMINSTER ABBEY
}





\section{WESTMINSTER ABBEY RICHARD JENKYNS}

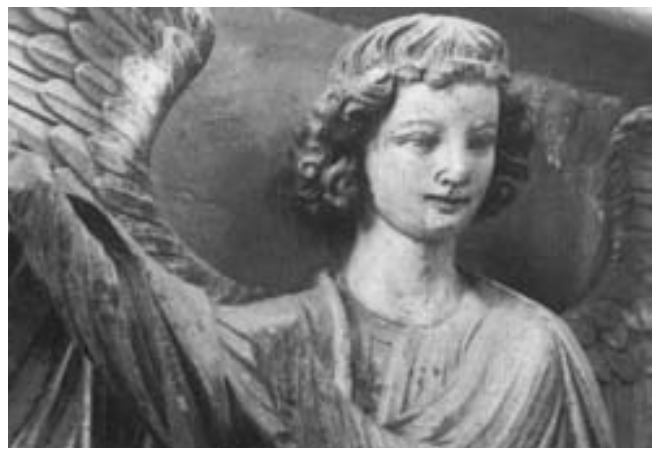

HARVARD UNIVERSITY PRESS

Cambridge, Massachusetts 2005 
Copyright (C 2004 by Richard Jenkyns

First published in the United Kingdom in 2004 by Profile Books Ltd 58A Hatton Garden London ECIN 8LX

Library of Congress Cataloging-in-Publication Data

Jenkyns, Richard

Westminster Abbey / Richard Jenkyns.

p. cm.

Includes bibliographical references and index. ISBN o-674-oi7i6-i (alk. paper)

I. Westminster Abbey-History. I. Title.

DA687.W5J34 2005 283'.42132-dc22 $200405433^{12}$ 